\title{
Primary atlantoaxial bone tumors in children: management strategies and long-term follow-up
}

\author{
Clinical article
}

\author{
Arnold H. Menezes, M.D., and Raheel Ahmed, M.D., Ph.D. \\ Department of Neurosurgery, University of Iowa Hospitals and Clinics, Iowa City, Iowa
}

\begin{abstract}
Object. Atlantoaxial tumors account for a substantial proportion of primary bone tumors in children. Before resection, surgeons must consider the complex regional anatomy, the potential for neurological compromise, craniocervical instability, and the question of tumor resectability in a growing spine. Using current technology, the authors analyzed surgical cases in this light and present outcomes and treatment recommendations after long-term patient follow-up.

Methods: The authors reviewed clinical records for 23 children whose primary atlantoaxial bone tumors were treated from 1996 through 2010.

Results. Pathological lesions among the 23 patients were 4 aneurysmal bone cysts, 2 osteochondromas, 5 chordomas, 4 osteoblastomas, 3 fibrous dysplasias, 4 eosinophilic granulomas, and 1 Ewing's sarcoma. Clinical presentation consisted of neck pain $(n=23)$, headaches and occipital pain $(n=16)$, myelopathy $(n=8)$, and torticollis ( $n$ $=4$ ). Selective angiography and coil embolization were undertaken for all patients with aneurysmal bone cysts and osteoblastomas, 2 patients with chordomas, 1 patient with fibrous dysplasia, and 1 patient with Ewing's sarcoma. Primary embolization treatment of radiation-induced aneurysmal bone cyst of the atlas showed complete reossification. Results of CT-guided needle biopsy were diagnostic for 1 patient with eosinophilic granuloma and 1 with Ewing's sarcoma. Needle biopsies performed before referral were associated with extreme blood loss for 1 patient and misdiagnosis for 2 patients. Surgery involved lateral extrapharyngeal, transoral, posterior, and posterolateral approaches with vertebral artery rerouting. Complete resection was possible for 9 patients ( 2 with osteochondroma, 3 with fibrous dysplasia, 2 with chordoma, and 2 with osteoblastoma). Decompression and internal fusion were performed for 3 patients with aneurysmal bone cysts. Of the 23 patients, 7 underwent dorsal fusion and 4 underwent ventral fusion of the axis body. Chemotherapy was necessary for the patients with eosinophilic granuloma with multifocal disease and for the patient with Ewing's sarcoma. There was no morbidity, and there were no deaths. All patients with benign lesions were free of disease at the time of the follow-up visit (mean \pm SD follow-up $8.8 \pm 1.1$ years; range 2-18 years). Chordomas received proton or LINAC irradiation, and as of 4-15 years of follow-up, no recurrence has been noted.

Conclusions. Because most atlantoaxial tumors in children are benign, an intralesional procedure could suffice. Vascular control and staged resection are critical. Ventral transoral fusion or lateral extrapharyngeal fusion has been successful. Resection with ventral fusion and reconstruction are essential for vertebral body collapse. Management of eosinophilic granulomas must be individualized and might require diagnosis through needle biopsy.
\end{abstract}

(http://thejns.org/doi/abs/10.3171/2013.11.PEDS13245)

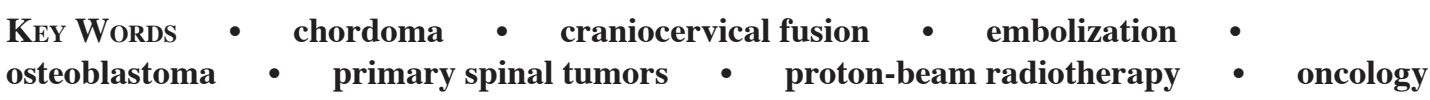

$\mathrm{T}$ UMORS of the spine are rare and represent $2 \%-8 \%$ of all musculoskeletal tumors in children. The most common benign vertebral tumors are eosinophilic granulomas (12\%-25\%), osteoid osteoma/osteoblastomas $(12 \%)$, and aneurysmal bone cysts $(10 \%) .^{14,22,27}$ The most common malignant primary vertebral tumor in children is Ewing's sarcoma. ${ }^{6,14}$ With the advent of high-definition imaging of bone tumors, it is natural to extrapolate the staging system used for tumors in long bones to those in the spine.$^{10,21}$ High-definition imaging is useful for predicting the extent of resection and follow-up needed.
Atlantoaxial tumors in children comprise a distinct entity because of the complexity of the regional anatomy (brain, cervical cord, cranial nerves, CSF spaces, and vascular structures); craniocervical stability in a transitional zone; and skeletal growth potential. Thus, tumor resectability depends on the location and biological aggressiveness of the lesion. ${ }^{56} \mathrm{~A}$ surgeon considering en bloc tumor resection should take into account the benign or malignant nature of the lesion and the potential involvement of neurovascular structures. The atlantoaxial region accounts for more than $25 \%$ of primary bone tumors in children. ${ }^{6,22,41,42}$ 
Careful analysis of this series with long-term outcomes is presented as a balanced, meaningful approach to tumors in this region.

\section{Methods}

Our review spans the MRI era: 1996-2010. All research was approved by the University of Iowa Institutional Review Board. Multiple institutional databases were searched for the following inclusion criteria: age younger than 16 years at diagnosis, histopathological findings consistent with origination from vertebral bone, and clinical diagnosis during 1996-2010. These databases searched the institutional tumor registry, records of inpatient and outpatient visits, and pediatric neurosurgery and neuroradiology databases. Of 87 children with primary spinal tumors at all levels, 23 with primary atlantoaxial tumors were identified. Medical records were reviewed and attention was given to symptoms and signs, imaging findings, disease extent, treatment received, histopathological findings, complications, and long-term outcomes.

\section{Results}

From 1996 to 2010, a total of 23 children underwent treatment for atlantoaxial tumors at the Pediatric Neurosurgery Service at University of Iowa Hospitals and Clinics. Of these, 22 were designated as having benign tumors and 1 had a malignant Ewing's sarcoma. Specifically, pathological examination identified 4 aneurysmal bone cysts, 5 chordomas, 2 osteochondromas, 4 osteoblastomas, 3 fibrous dysplasias, 4 eosinophilic granulomas, and 1 Ewing's sarcoma.

\section{Clinical Presentation}

Of the 23 patients, 15 were male and 8 were female; the mean age $( \pm$ SD) was $10.5 \pm 1.0$ years (range 3-16 years). The mean $( \pm \mathrm{SD})$ follow-up duration was $8.8 \pm 1.1$ years (range 2-18 years). Table 1 summarizes the clinical presentation, treatment, and final outcomes for all 23 patients. Cases 7 and 10 have been reported elsewhere..$^{41,43}$

For nearly all patients, the predominant symptom was neck pain. Neurological deficit was a presenting sign for 9 patients (39\%); quadriparesis was noted for 5 patients (22\%). Precipitating events included wrestling for 2 patients, induction of general anesthesia for 2 patients with osteochondroma, and cheerleading for 1 patient in whom increasing neck pain with motor weakness developed. One patient with eosinophilic granuloma became symptomatic while wrestling at school.

Initial evaluation comprised plain radiography and CT and MRI of the cervical spine. Bone and PET scanning were performed when an underlying eosinophilic granuloma was suspected. Either CT angiography or MR angiography was performed for each patient to identify the course of the vertebral artery in relation to the tumor for the planned surgical approach or to determine tumor involvement. Preoperative tumor embolization was performed for a patient with a large vascular osteoblastoma, a 16-year-old patient with an aneurysmal bone cyst, as a definitive procedure for a patient with radiation-induced aneurysmal bone cyst, and before staged excision for a patient with a C-2 chordoma. One patient underwent embolization for a vascular lesion identified on MR images that was later determined to be fibrous dysplasia.

The patient in Case 5, who had an osteoblastoma, underwent a CT-guided needle biopsy that was not diagnostic. One patient with an aneurysmal bone cyst underwent a CT-guided biopsy before referral, during which she experienced substantial $(600 \mathrm{ml})$ blood loss. She later underwent preoperative embolization before resection. A CT-guided biopsy was diagnostic for 2 patients (the patient in case 15 had an underlying Ewing's sarcoma and the patient in case 23 had an eosinophilic granuloma). For the patient in Case 16, who had fibrous dysplasia, indeterminate needle biopsy results indicated multinucleated giant cells.

\section{Surgical Treatment}

Surgical management was based on a preliminary diagnosis determined from imaging. Imaging studies were also used to define the extent of the lesion and its resectability. Preoperative angiography involving the vertebral arteries was undertaken to determine tumor vascularity and viability of vessel sacrifice to optimize tumor resection. A ventral transoral resection was always followed by stabilization (with bone graft placed directly into the resection bed) and dorsal fixation. Surgical approaches were staged and customized for each patient. The 2 patients with chordoma received LINAC irradiation. Two other patients with chordoma elected to undergo proton beam treatment.

Six patients ( 2 with osteochondromas, 2 with osteoblastomas [Cases 5 and 6], and 2 with aneurysmal bone cysts [Cases 8 and 9]) underwent primary en bloc resection. Among the 5 patients with chordomas, 2 underwent resection by a transoral approach (Cases 11 and 13), and 1 (Case 14) underwent resection by a lateral extrapharyngeal approach. Complete resection was possible for the 3 patients with fibrous dysplasia. Most patients underwent staged resection followed by spinal stabilization.

\section{Clinical Outcomes}

Of the 5 patients with chordomas, no recurrence was seen at a mean $( \pm$ SD) follow-up time of $8 \pm 1.8$ years (range 2-16 years). The patient with Ewing's sarcoma underwent biopsy, chemotherapy, and subsequent bone marrow transplantation and was alive and disease free as of the 8-year follow-up visit. All patients underwent postoperative imaging immediately after the procedure and subsequently underwent serial plain radiography and CT to document re-formation of vertebral bodies or osseous integration into the fusion construct. No infections were detected in any patients, including those who underwent an anterior transoral decompression and fusion. Re-fusion after radiation was needed by the patient in Case 5 (atypical osteoblastoma); at the 16-year follow-up visit, the fusion construct was stable. For 1 patient with eosinophilic granuloma within the odontoid process, additional disease 
A. H. Menezes and R. Ahmed

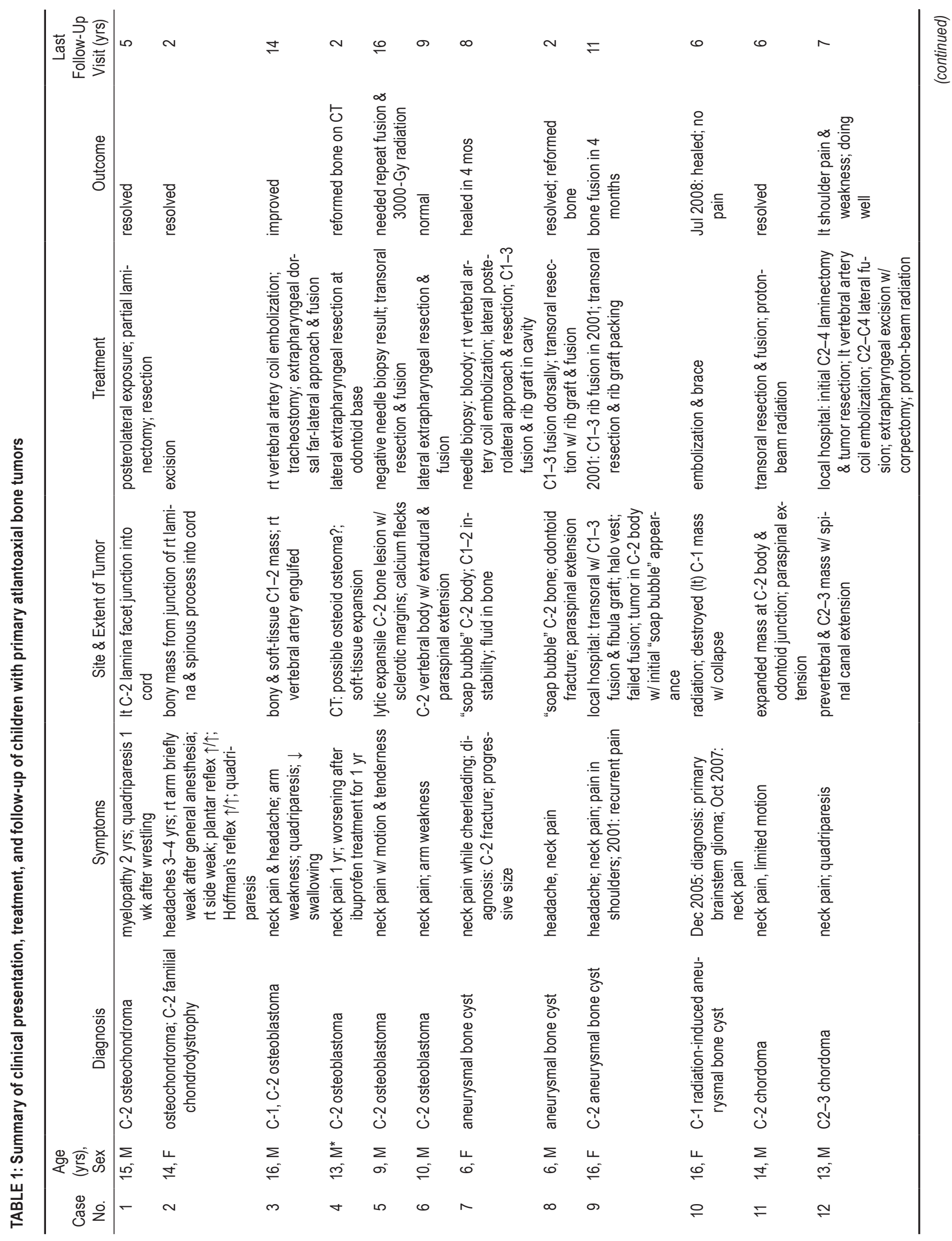


Atlantoaxial bony tumors in children

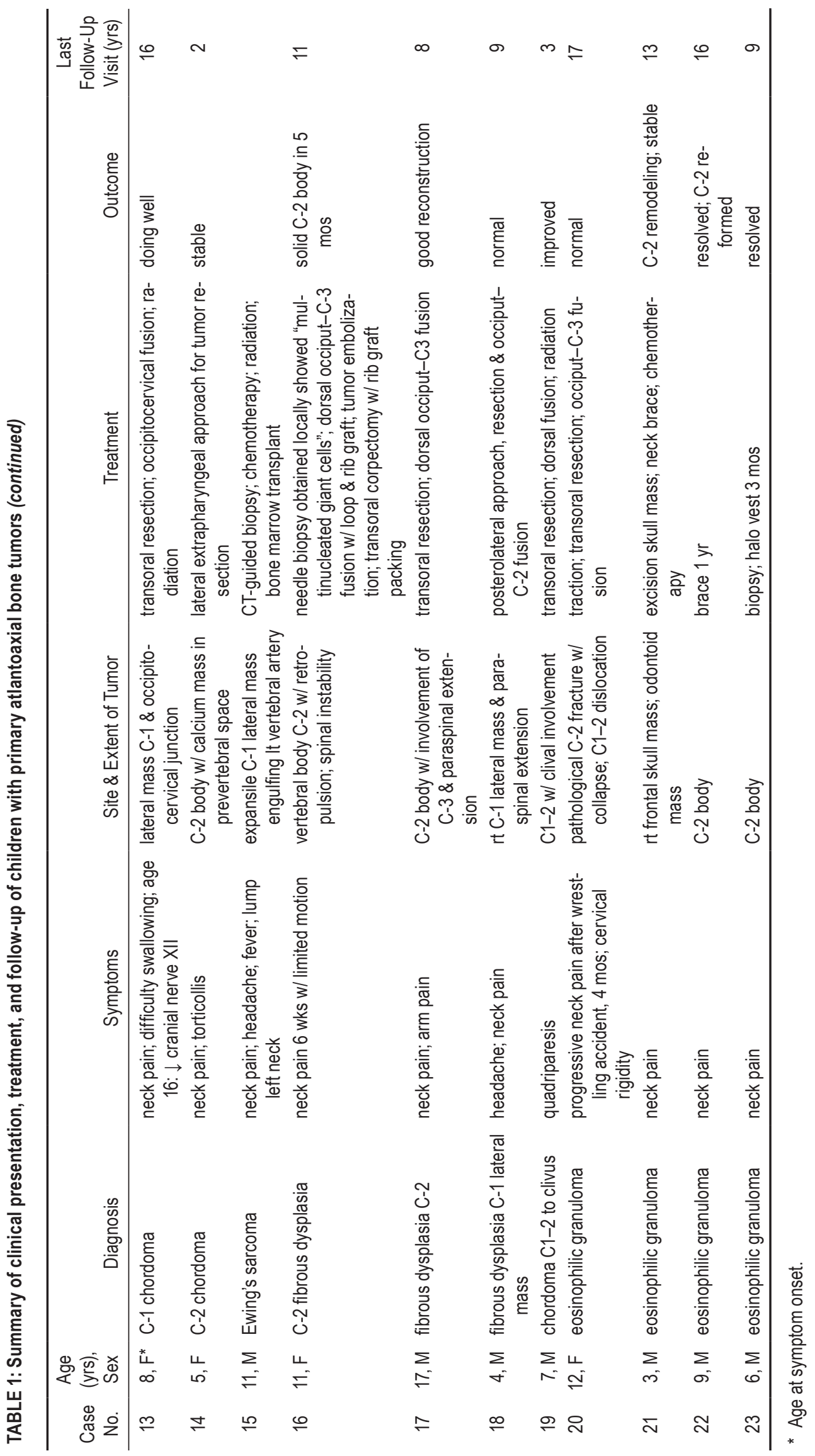




\section{A. H. Menezes and R. Ahmed}

developed within the right frontal skull. The skull mass was excised and provided the histopathological diagnosis. This patient later underwent chemotherapy and neck stabilization with a brace. Remodeling of the axis body was demonstrable on 2-year follow-up imaging; no disease recurrence was noted during the 13 years of follow-up.

\section{Illustrative Cases}

\section{Case 10}

This 16-year-old girl experienced gait ataxia, difficulty swallowing, and double vision. Examination revealed palsies of the left cranial nerves VI, VII, and VIII, diminished gag reflex bilaterally, and marked gait difficulty. Brain MR images indicated a brainstem glioma for which she underwent LINAC irradiation with 5500 Gy and received temozolomide (Fig. 1A). After 18 months, she was examined because of headaches, neck pain, and left head tilt (Fig. 1B). On CT and MR images, the left C-1 lateral mass was markedly compressed and trabecular bone had been lost (Fig. 1C). This finding was believed to represent a radiation-induced aneurysmal bone cyst. The patient was treated with left vertebral artery coil embolization and was immobilized in an Aspen cervical brace (Cascade). At the 12-month follow-up visit, reconstitution of the left C-1 lateral mass was good, and it had fused to the left occipital condyle (Fig. 1D). At the 6-year follow-up visit, her symptoms had resolved and her glioma was stable.

\section{Case 7}

This 6-year-old girl had a 4-month history of neck pain and tingling in her hands, which had started after cheerleading activities. After evaluation by the referring surgeon, an external cervical collar was prescribed; the child was subsequently unable to hold her head up without the collar. After imaging, she underwent CT-guided biopsy of a C-2 body lesion, during which she lost 600 $\mathrm{ml}$ of blood. Findings were inconclusive. She was referred to one of the authors (A.H.M.), to whom she complained of continuing symptoms. She was grossly hyperreflexic throughout the examination. Imaging revealed a honeycombed appearance of the odontoid process and axis body, which extended into the right facet and pedicle (Fig. 2A). A soft-tissue mass extended into the spinal canal and had increased over the previous 2 months. A vertebral body fracture with displacement into the spinal canal was observed. Through a lateral-posterolateral approach to the upper cervical spine, the right vertebral artery, which had been preoperatively embolized, was rerouted (Fig. 2B). The odontoid process and axis body were packed with rib graft (Fig. 2C). Given the underlying atlantoaxial instability, the patient underwent dorsal $\mathrm{Cl}-3$ bilateral interlaminar rib graft fusion. At the 4-month follow-up visit, the rib grafts were incorporated into the lamina between C-1 and C-3 and the axis body was reconstituted (Fig. 2D).

\section{Case 4}

This 13-year-old boy, with underlying moderate psychomotor developmental delay, was evaluated for tho-
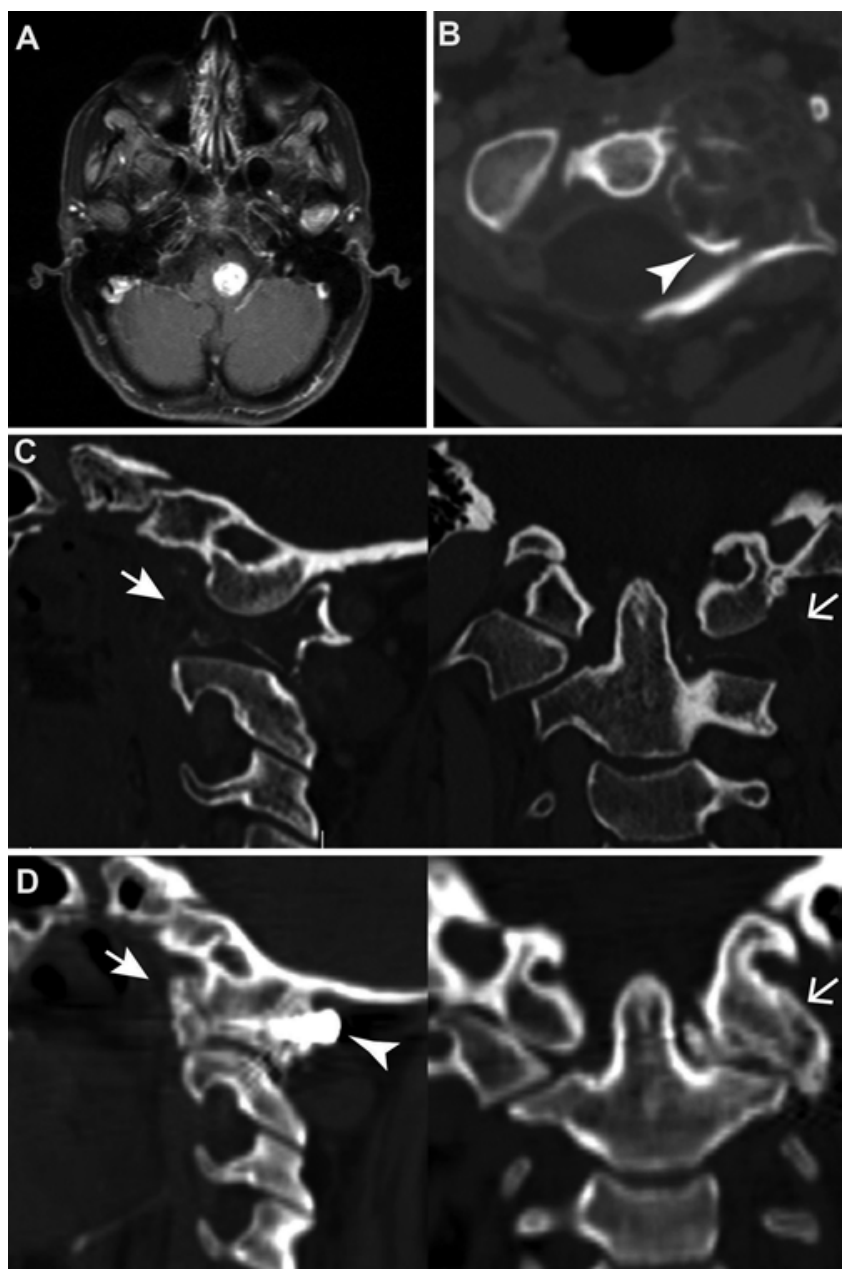

Fig. 1. Case 10. A 16-year-old girl with a postirradiation aneurysmal bone cyst. A: Axial T1-weighted MR image showing a contrastenhanced brainstem glioma. B: Axial CT image through the axis vertebra. Note the expansile, lytic, "bubbly" appearance with sclerotic margins (arrowhead) arising from the left C-1 lateral mass. C: Sagittal (left) and coronal (right) 2D CT images showing osteolytic appearance with collapse of the left C-1 lateral mass (arrows). D: Sagittal (left) and coronal (right) 2D CT images through the left C-1 lateral mass 12 months after embolization of the left vertebral artery and craniocervical bracing. Arrowhead denotes coil. Note the bony remodeling.

racic scoliosis. Spinal CT showed a C-2 abnormality. Six months later, the boy complained of neck pain, which was intermittent, worse in the morning, and relieved by ibuprofen. A CT-based diagnosis of probable osteoid osteoma at C-2 was followed with serial imaging (Fig. 3A). A year later, the boy complained of increasing neck pain. Spinal CT showed that the lesion had broken out of its borders and had a soft-tissue mass around it with encroachment on the anterior arch of the atlas (Fig. 3B). There was enhancement with Gd on MR images. Given the local mass effect with suspicion of transformation to an osteoblastoma, a lateral extrapharyngeal approach was undertaken; the anterior atlas arch, odontoid process, and axis body were exposed. Cranial nerves VII, IX, X, and XII were monitored. The lesion was excised, and the cavity was packed with autologous rib graft. Computed tomography showed good healing 1 year later, after which the thoracic scolio- 

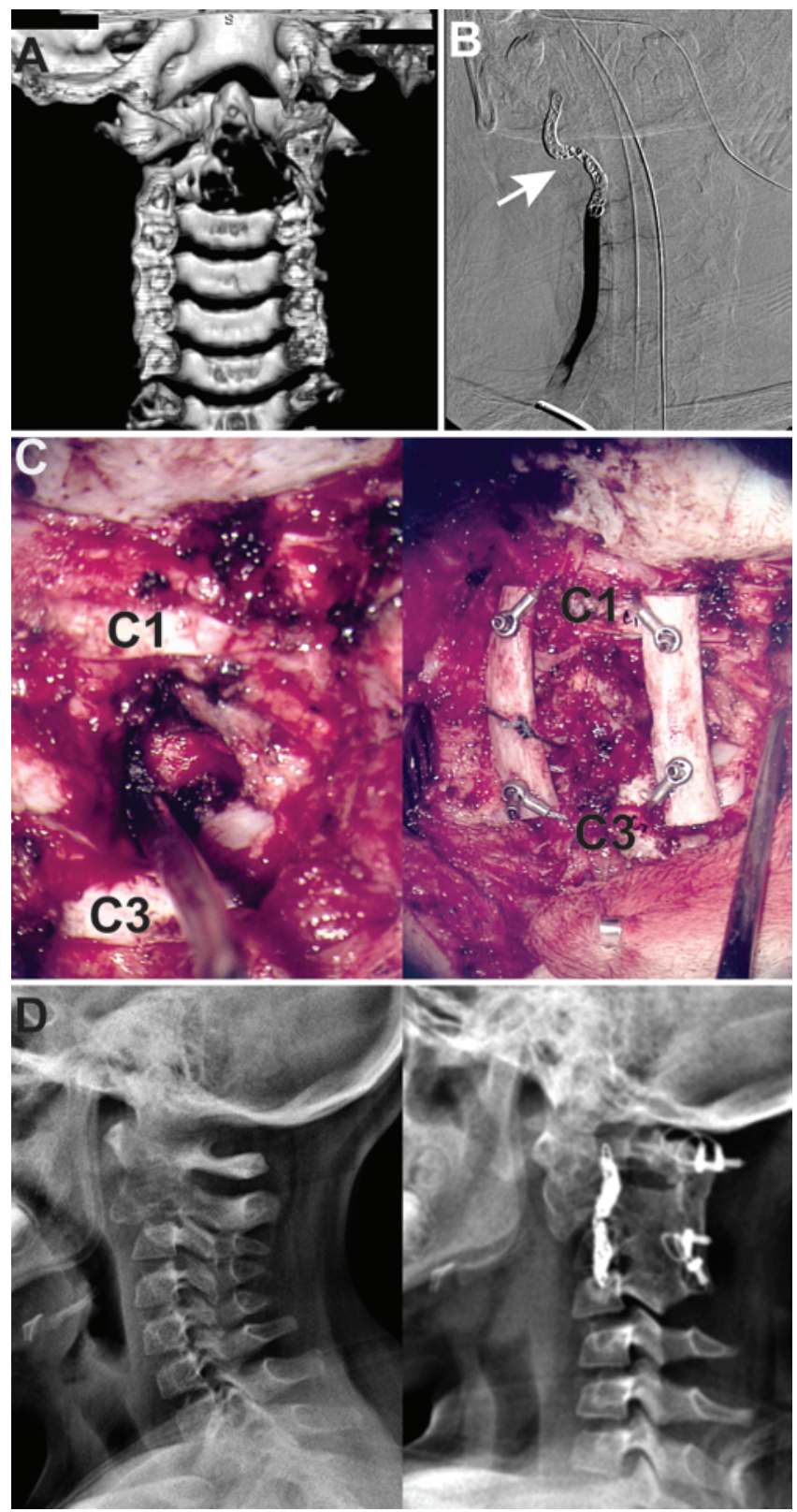

Fig. 2. Case 7. A 6-year-old girl with an extensive C-2 aneurysmal bone cyst. A: 3D CT reconstruction of the cervical spine. Note the "moth-eaten" appearance of the axis. B: Preoperative embolization and sacrifice of the right vertebral artery (arrow). C: Intraoperative photographs via a right posterolateral and dorsal midline approach, showing the resection cavity (left) and bilateral interlaminar fusion with rib (right). D: Comparison of preoperative (left) and postoperative (right) cervical spine radiographs, showing stable alignment and bony dorsal $\mathrm{C} 1-3$ fusion and axis body reconstitution.

sis was corrected surgically (Fig. 3C). The diagnosis was osteoblastoma.

\section{Case 3}

This 16-year-old boy was evaluated for neck pain and arm weakness that progressed to paraparesis and subsequently to quadriparesis and difficulty swallowing. Imaging revealed a large C-1 mass engulfing the right vertebral artery, with associated atlantoaxial instability. The boy was referred to one of the authors (A.H.M.) and subsequently underwent preoperative vertebral artery angiography and coil embolization of the right vertebral artery (Fig. 4). Because the patient experienced cranial nerve palsies, a tracheostomy was made. He initially underwent a lateral extrapharyngeal approach for ventral tumor resection with skeletonization of the vertebral artery. He subsequently underwent a dorsal far-lateral approach, removal of residual tumor, and an occipitocervical fusion. By his last follow-up visit 14 years later, the neurological deficit had improved significantly.

\section{Case 16}

This 11-year-old girl was evaluated for a 6-week history of severe neck pain with limitation of neck movement. Imaging revealed replacement of the odontoid process and axis body with an enhancing mass and some degree of retropulsion of the axis body into the spinal canal (Fig. 5A). A cervical collar provided symptom relief. A needle biopsy sample was taken and was interpreted as showing multinucleated giant cells. The girl was referred to our institution for further evaluation. The first stage of her surgical management consisted of a dorsal occiput-C3 fusion with titanium loop instrumentation and rib graft. She then underwent angiography and tumor embolization through the ascending pharyngeal artery (Fig. 5B). A transoral approach was used for tumor resection within the $\mathrm{C}-2$ body, which was packed with rib graft bone that had been saved from the dorsal procedure (Fig. 5C). At the 6-month follow-up visit, there was complete reconstitution of the vertebral body (Fig. 5D). The diagnosis was fibrous dysplasia. The girl remained asymptomatic through her 11-year follow-up period.

\section{Case 13}

At 8 years of age, this girl was evaluated for neck pain and difficulty swallowing. Her symptoms progressed, and by age 16 she experienced substantial speech difficulty. At that time, she was referred to one of the authors (A.H.M.) and had a markedly diminished gag reflex, diminished hearing bilaterally, bilateral partial palsy of cranial nerve XII, and an ataxic gait. Imaging confirmed a mass eroding the occipital condyles and a C-1 lateral mass with intradural invasion (Fig. 6A). The girl underwent crown halo cervical traction, transoral-transpalatopharyngeal tumor resection, and a CSF leak repair with fascial and fat graft (Fig. 6B). She subsequently underwent dorsal occipitocervical stabilization. The girl remained disease free through her 16-year follow-up after surgery. Final histopathological diagnosis was chordoma.

\section{Case 2}

This 14-year-old girl was evaluated for a 3- to 4-year history of severe headaches, which worsened after she underwent general anesthesia for removal of femoral osteochondromas. She briefly lost function in both arms. She was treated for migraines. She also had a family history of chondrodystrophy. Examination revealed moderate weakness of the right arm and right leg; the patient 

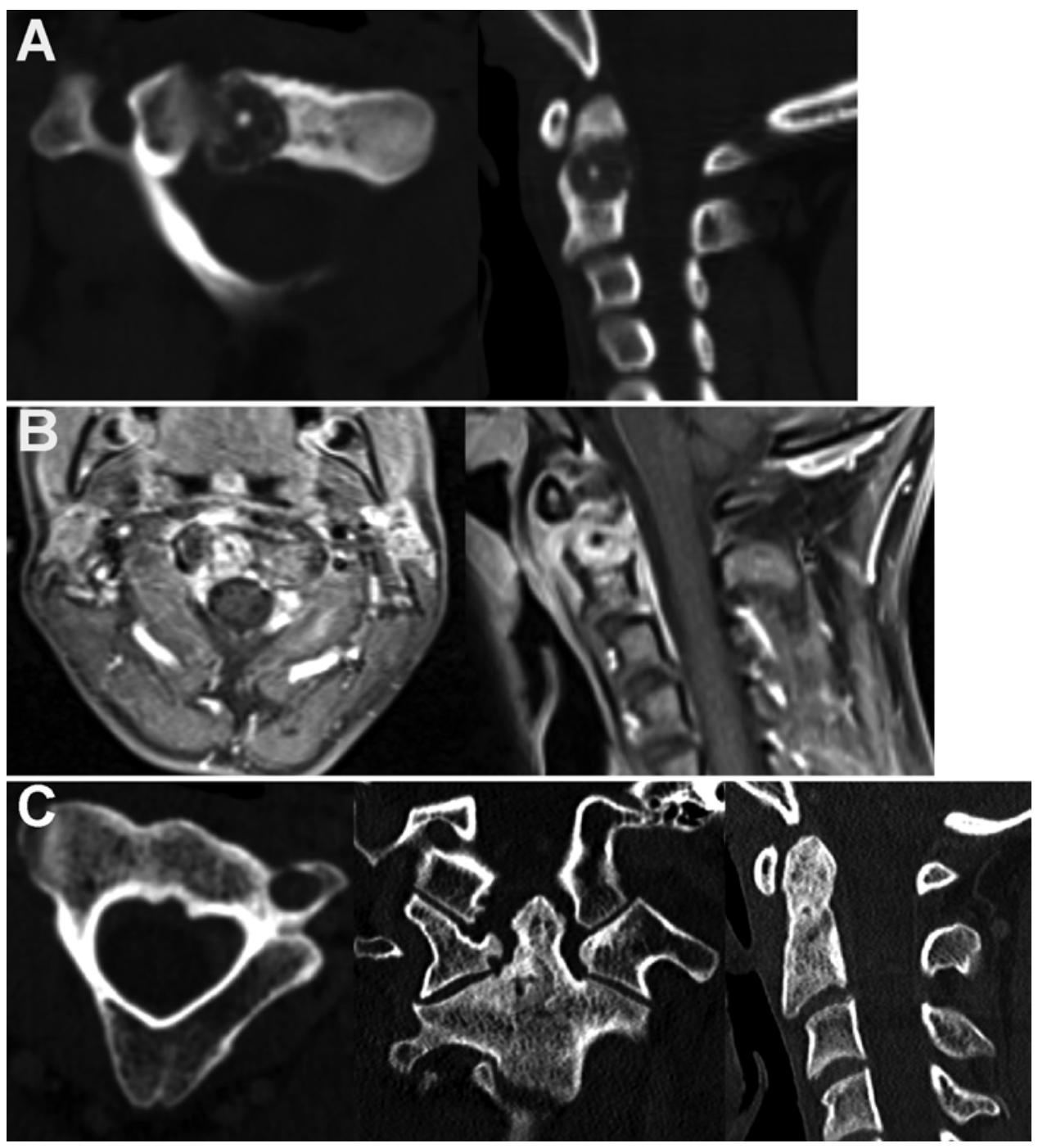

FIG. 3. Case 4. A 14-year-old (13 years of age at symptom onset) boy with osteoblastoma. A: Axial and sagittal CT scans. Note the "target sign" in the odontoid-axis body junction, presumably osteoid osteoma. B: Axial (left) and sagittal (right) T1weighted MR images with contrast. Note the enhancing soft tissue with expansion. C: Axial, coronal, and sagittal CT images. These follow-up images show complete odontoid axis bony remodeling.

was grossly hyperreflexic throughout the examination and exhibited bilateral Hoffman and Babinski responses. Imaging showed marked spinal compression from an osteochondroma arising from the junction of the C-2 lamina and spinous process. (Fig. 7A and B). A posterior midline approach was made, and an en bloc resection of the lamina and spinous process on the right was performed under neurophysiological monitoring (Fig. 7C). Final pathological findings were consistent with osteochondroma, and the patient's postoperative course was unremarkable.

\section{Discussion}

Primary tumors of the spine in children are infrequently encountered. ${ }^{66}$ Since 1956 , our entire series of tumors found in all sections of the spine in children has amounted to 87 tumors. Of these, 42 were found from 1996 through 2010, and 23 of these were at the atlanto- axial level. Thus, there is a preponderance of primary spine tumors at this level among children. Schomacher et al. provided a review of osteochondromas through $2007,{ }^{62}$ of which $43 \%$ were at the C1-2 level. Because of the preponderance of primary spinal tumors in this region and the early development of neurological deficits caused by local tumor growth patterns, we propose that atlantoaxial tumors in children constitute a distinct clinical entity. Furthermore, the underlying osseous and musculoligamentous stability at the transitional craniovertebral junction must be taken into account with regard to tumor spread and surgical treatment. We demonstrated successful tumor control by complete intralesional resection. ${ }^{42}$

In 1996, Piper and Menezes presented surgical management strategies for tumors of the axis in adults and children. ${ }^{56}$ The approaches were as follows: 1) the anterior transoral-transpalatopharyngeal route (Zone 1), with exposure from a facet joint to the opposite facet joint; 2) 

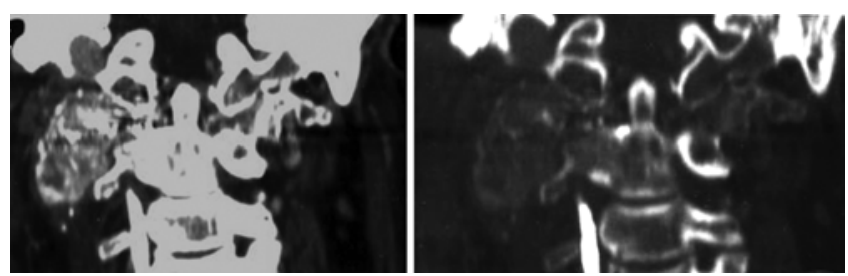

FIG. 4. Case 3. A 16-year-old boy with osteoblastoma. Coronal 2D CT angiograms of craniovertebral junction after right vertebral artery occlusion. Note the destruction of the atlas lateral masses.

the lateral extrapharyngeal route, with the same exposure but from an anterolateral approach going onto the foramen transversarium (Zone 2); 3) the posterolateral approach with vertebral artery rerouting that exposes the foramen transversarium and both laminae up to the foramen transversarium on the side of approach (Zone 3); and 4) the midline approach from a dorsal aspect, which provides exposure between the right and left facets (Zone 4).

In 1980, Enneking et al. ${ }^{21}$ defined surgical staging of musculoskeletal sarcomas for limb lesions. Tumor stage was defined by surgical grade (G), local extent (T), and regional or distant metastases $(\mathrm{M})$, irrespective of the underlying histopathological findings. In 1997, Boriani et al. ${ }^{10}$ described terminology and surgical staging of primary bone tumors of the spine, which could be considered as an extrapolation of the Enneking et al. classification. For visualization of the extent of the lesion, this surgical staging system relied on axial transverse sections and divided them into 12 clockwise-radiating zones and 5 concentric layers, from paravertebral extraosseous to dural involvement. They believed that en bloc resection should be attempted but agreed that benign tumors could be excised intralesionally unless they were aggressive.

En bloc resection of primary spinal tumors has been attempted mainly in adults and infrequently in children and even less within the upper cervical spine. Fisher et al. reported their institutional experience of applying the principle of wide resection, commonly used for appendicular musculoskeletal tumors, to surgical treatment of primary spinal tumors. ${ }^{25}$ The study population comprised 26 adults, of which 19 had malignant lesions. Severe complications occurred in 24 of these 26 patients, and massive blood loss (more than $5,000 \mathrm{ml}$ ) occurred in 11. A systematic review of 89 articles pertaining to the Weinstein/ Boriani staging classification with wide excision concluded that tumor recurrence clearly increased when intralesional procedures were performed before the definitive en bloc resection. ${ }^{69}$ Tumor recurrence significantly shortened survival times, and the surgical complication rate ranged from $13 \%$ to $56 \%$. Bandiera et al. reported complications for 72 of 134 patients who underwent en bloc resections for spinal tumors from 1990 through $2007 .{ }^{4}$ Some of these complications were immediate, some were delayed, and some included death. Thus, although en bloc resection of

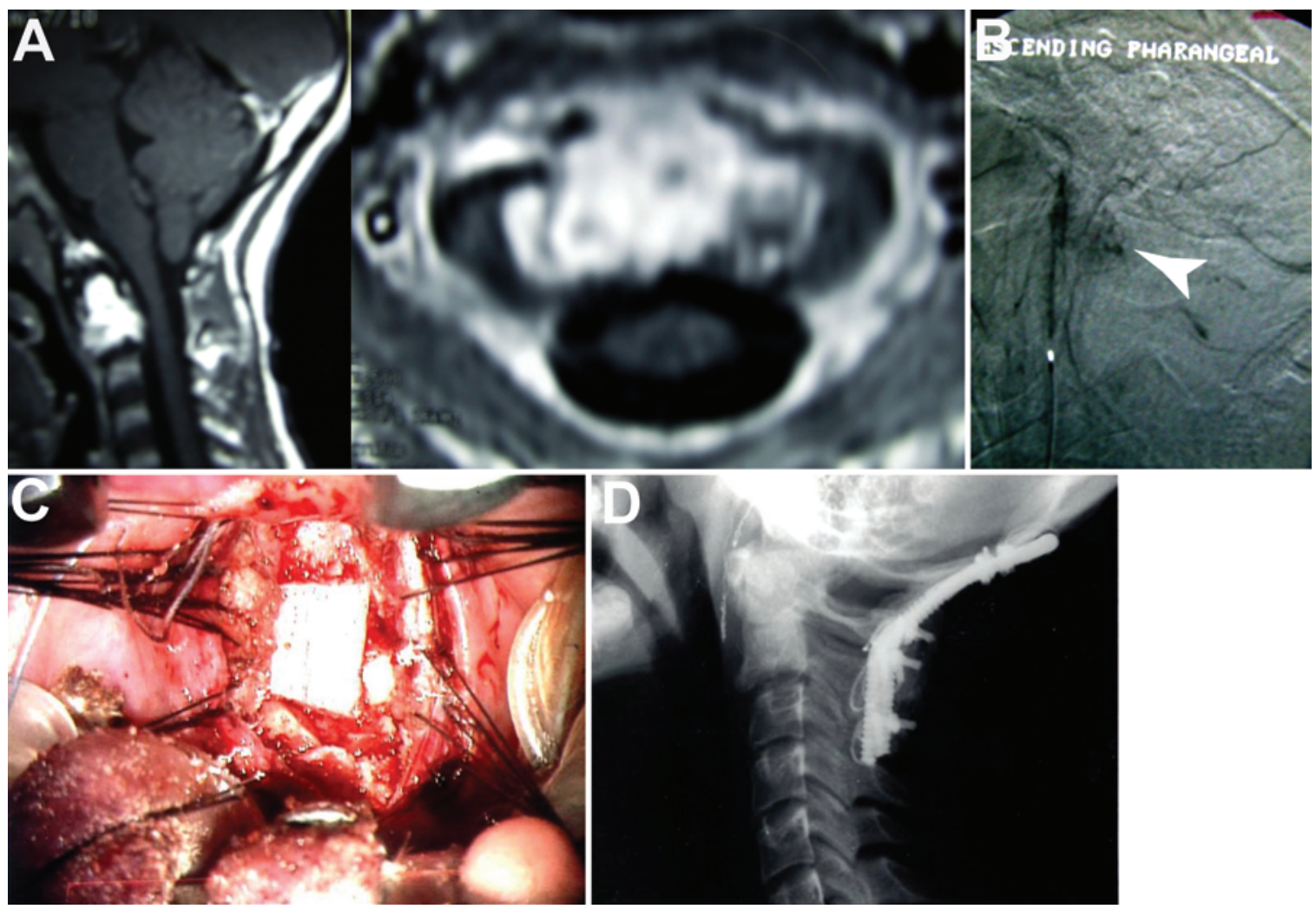

Fig. 5. Case 16. An 11-year-old girl with fibrous dysplasia. A: T1-weighted postcontrast MR images, sagittal (left) and axial (right) views, at C-2. Note the enhanced mass in the axis body. B: Preoperative angiogram with ascending pharyngeal artery injection demonstrating tumor blush (arrowhead). C: Intraoperative photograph demonstrating C-2 corpectomy via transoral route. The resection cavity is filled with rib graft. D: Lateral cervical spine radiograph taken 6 months after surgery. Note the dorsal occiput-C3 fusion and remodeling of the axis body. 

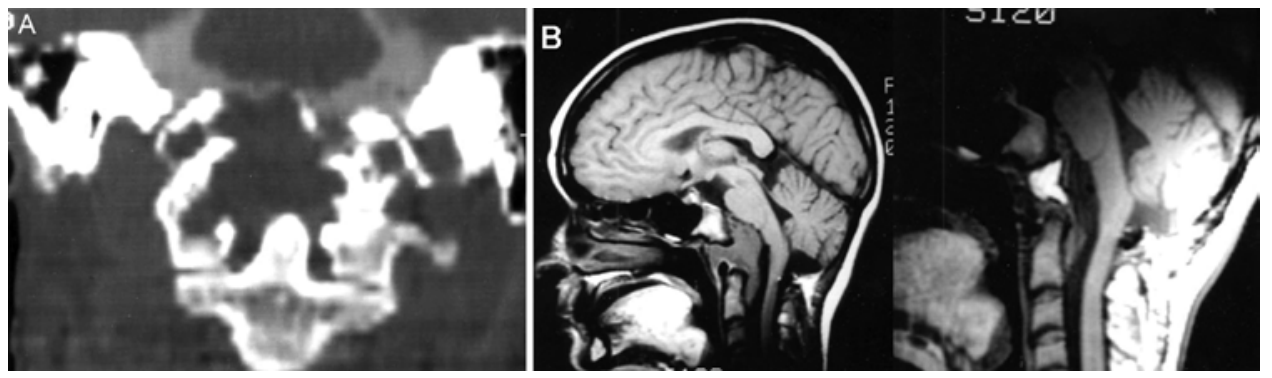

FIG. 6. Case 13. A 16-year-old (8 years of age at symptom onset) girl with longstanding occipitocervical pain from chordoma. A: Coronal CT scan of occipitoatlantal region through the plane of the odontoid process. Note the destruction of the occipital condyles and lateral atlantal masses. B: Midsagittal T1-weighted MR images before (left) and after (right) ventral transoral resection. Note replacement of the atlas and large ventral craniovertebral mass with cervicomedullary compression (left). The tumor invaded the subarachnoid space, necessitating closure with fascia and fat (right) after resection.

primary spinal tumors might be the ideal treatment goal, it must be weighed against the associated complications from these radical procedures, especially for children. ${ }^{70}$ Given the treatment factors outlined earlier, this management principle is also especially pertinent to atlantoaxial tumors. Our case series provides a balanced and individualized approach, based on radical and conservative surgical approaches (Table 1).

Most authors agree that for patients with suspected malignancies, percutaneous CT-guided biopsies of osseous lesions of the spine are safer than an open technique. In 2004, Lis et al. reported an accuracy rate of $89 \%$ in their experience with $410 \mathrm{CT}$-guided spine biopsies ${ }^{37}$ For 9 patients they were able to harvest only blood, and only $2 \%$ of all malignancies were in the cervical spine. Thus, CT-guided biopsy is a useful tool for the workup of patients with known or suspected malignancy at the cranio- cervical region. However, a CT-guided needle biopsy is not recommended for vascular lesions, such as aneurysmal bone cysts, but can be considered essential for suspected eosinophilic granulomas, Ewing's sarcomas, osteogenic sarcomas, and chordomas. ${ }^{2,5,10,14,22,23,25,27,31,45,68}$

For patients with spine tumors, improved imaging techniques have shortened the time from symptom development to diagnosis. ${ }^{22}$ Both $\mathrm{CT}$ and MR imaging are widely used. Computed tomography angiography and MR angiography have become increasingly useful for defining pertinent vasculature with fine resolution because these noninvasive studies are associated with less risk and can be routinely used to help the surgeon decide when conventional angiography with or without embolization is necessary. Three-dimensional CT reconstructed imaging is widespread and is routinely used at our institution for preoperative mapping and planning.
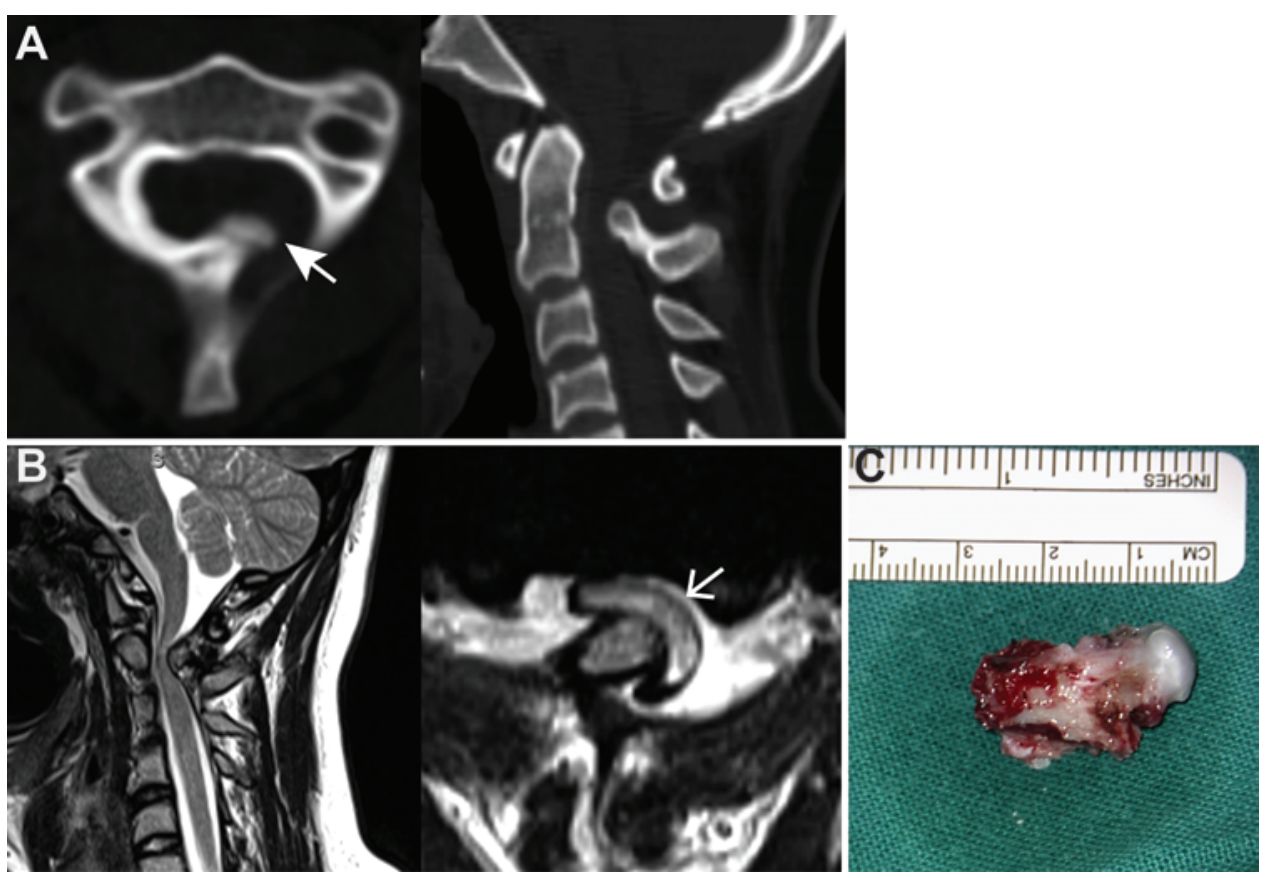

FIG. 7. Case 2. A 14-year-old girl with osteochondroma. A: Axial CT scan through C-2 and midsagittal 2D CT scan. Note the bony mass arising from the lamina-spinous process junction into the spinal canal (arrow). B: Midsagittal T2-weighted MR image (left) of the upper cervical spine and axial view (right). Note the extreme spinal cord compression (arrow). C: Gross specimen demonstrating characteristic cartilaginous cap of the osteochondroma. 
Preoperative embolization of vertebral tumors has proven to be a useful adjunct to surgery. It facilitates resection by minimizing blood loss and enables safer resection. ${ }^{17,19,22,30,43,54,63}$ The estimated blood loss during resection of spinal column neoplasms after embolization $(1.5-2.2 \mathrm{~L})$ is less than that lost when preoperative embolization is not performed $(9.5-12 \mathrm{~L}) .^{22,63}$ When feasible, provocative testing before definitive occlusion is performed to reduce complications associated with the embolization procedure. ${ }^{22}$ In our series, this procedure was performed for the patients in Cases 3, 7, 10, 12, and 16. For the patient in Case 7, temporary balloon occlusion of the left vertebral artery was performed because the vessel was encased by cervical chordoma. The patient did not exhibit any transient deficit, and the vessel was permanently occluded by coil embolization, which enabled extensive en bloc surgical resection and an excellent outcome. Transarterial embolization of a radiation-induced aneurysmal bone cyst (Case 10) was the mainstay of treatment; results were excellent.

Tumor involvement of the atlas and axis can destroy the articulation of the lateral masses or the vertebral bodies, resulting in pathologic fracture and/or gross spinal instability. This loss of stability is also observed after tumor destruction of the occipital condyle and lateral atlantal masses in patients with chordomas. It is present in more than $50 \%$ of patients with craniovertebral chordomas in the general population..$^{40,41,43}$ In the face of gross instability, atlantoaxial dorsal arthrodesis was performed for several patients. Rib grafts have been used for the procedure to complement instrumentation or as a primary means of fixation in very young children. To enable vertebral body remodeling, excess rib was banked and later used in the anterior corpectomy. Scheer et al. reviewed optimal construction techniques after $\mathrm{C}-2$ corpectomy and spondylectomy with biomechanical analysis. ${ }^{61}$ They showed that dorsal instrumentation should be supplemented by ventral cages or bone graft to accept skeletal loading at the atlantoaxial region.

\section{Primary Bone Tumors Affecting the Atlantoaxial Skeleton of Children}

Primary bone tumors can involve any portion of the spinal column and can extend in any direction. Tumors arising from posterior spinal elements are most commonly osteoid osteomas, osteoblastomas, osteochondromas, or aneurysmal bone cysts. ${ }^{27}$ However, the series reported here differed. For Case 4, the C-2 lesion started as an osteoid osteoma diagnosed on CT and progressed to soft tissue expansion with breakthrough of its cortical borders. The final pathologic diagnosis was osteoblastoma. These bone lesions are lytic and expansile with sclerotic margins and flecks of calcification within them. ${ }^{18}$ Osteoblastomas are expansile and not limited to the vertebral arch. The soft tissue mass together with retropulsion into the spinal canal leads to neurologic symptoms, and the pain is not easily relieved by aspirin. Osteoblastomas are rare and account for approximately $1 \%$ of primary bone tumors. Fortunately, complete resection is curative; ${ }^{22,24,32}$ incomplete resection, however, can lead to tumor recurrence..$^{11,44}$ Merryweather et al. reported malignant transformation in incompletely removed osteoblastoma and recurrence 9 years later as a sclerosing osteoblastic osteosarcoma with subsequent pulmonary metastasis. ${ }^{44}$ Of 30 children with osteoid osteomas and osteoblastomas identified from the Neurosurgery and Orthopedic services in Toronto (1993-2008), atlantoaxial osteoblastomas were identified in only 2 children (each 5 years of age). ${ }^{11}$ Osteoblastoma in the atlas has been reported, ${ }^{29}$ and a separate lesion in the odontoid process has been seen. ${ }^{33}$ Myles and MacRae described 10 patients in the Alberta, Canada, series, with "benign osteoblastoma of the spine in childhood." pointed out that persistence of pain after resection indicated incomplete resection and that these tumors responded well to reoperation and excision. Their average followup time was 66 months, and there were no recurrences. Azouz et al., in an earlier series, combined the experience of 4 institutions, for a total of 22 cases, ${ }^{3}$ of which 13 were osteoid osteomas and 9 were osteoblastomas. None were located at the atlantoaxial region. Kaner et al. pointed out that osteoid osteoma and osteoblastoma of the cervical spine caused persistent unusual neck pain and recommended CT or MR imaging. ${ }^{36}$ In our series, osteoblastoma at the atlas was extensive, and both lateral masses and anterior arch with dysphagia were involved. The patient in Case 3 had a vascular lesion that engulfed the vertebral artery. He required an urgent tracheostomy, after which the lesion was embolized and the right vertebral artery was occluded. He underwent resection through a high lateral extrapharyngeal approach for exposure of the ventral atlas surface and, subsequently, a dorsal posterolateral approach with further resection and occipitocervical fusion. One patient, who underwent radiation, required a fusion revision because of persistent instability. At 17 years after his procedure, he was neurologically stable with no signs of active disease.

Osteochondroma is the most common benign tumor of bone and comprises $9 \%$ of all bone tumors. Most osteochondromas arise in the appendicular skeleton and occur as solitary or multiple exostosis. ${ }^{35,38,65}$ The latter is part of an inherited, autosomal dominant condition called hereditary multiple exostosis. ${ }^{65}$ These lesions arise from epiphyseal herniation with a displaced portion of cartilage and hence the cartilaginous cap. They are external to the surface of bone but lie in continuity with the original bone. A literature review identified osteochondromas in $40 \%$ of solitary benign tumors; a spinal location was noted for $1 \%-4 \%$ of cases. ${ }^{62}$ Because up to $43 \%$ of spinal osteochondromas arise at the atlantoaxial level and $17 \%$ at C-7, they tend to occur at junctional-transitional areas. ${ }^{13,39,51,59,60,64}$ Tubbs et al. reported on a rare case of recurrent osteochondroma after incomplete resection. ${ }^{65}$ Our literature review indicated that all patients with multiple hereditary exostosis should undergo MRI of the spine because $27 \%$ will have spinal lesions.

Aneurysmal bone cysts are benign and comprise $1.4 \%$ of all bone tumors. ${ }^{2,12}$ They consist of unclotted venous blood under pressure that fills communicating bone spaces, which appear as "soap bubble" lesions that balloon the affected bone. , 28,47 Of the 289 aneurysmal bone cysts identified within the Mayo Clinic series (1910-1993), 52 were in the spine and all were in patients younger than 30 years of age. ${ }^{52}$ Collapse of the vertebral column was 


\section{A. H. Menezes and R. Ahmed}

common. These cysts commonly arose from the posterior bony elements and were most often treated by internal curettage and bone grafting. In 2001, Boriani et al. reported that of 41 cases of aneurysmal bone cysts, ${ }^{9}$ only 4 were in the atlas and 1 in the axis. According to their literature review to that date, up to $63 \%$ of aneurysmal bone cysts are prevalent among children. Malignant transformation of aneurysmal bone cysts was very rarely described and usually followed irradiation. The incidence of atlantoaxial aneurysmal bone cysts has been reported in the range of $11 \%$ to $16 \% .^{2,28,47}$ In our recent experience of 4 aneurysmal bone cyst at the atlas, we more commonly found odontoid fracture, fracture of the vertebral body, and collapse with instability. Our goal was arterial embolization followed by stabilization and tumor resection. Arterial embolization of the lesion has been accomplished with injection of calcitonin and methylprednisolone. . $^{9} 17,20,28,43,55,58,63,71$

Chordomas are rare, aggressive, destructive tumors presumed to be of notochordal origin; they arise along the vertebral axis, mainly in the foramen magnum, petroclival and sphenoclival regions. ${ }^{40,43}$ Chordomas are extradural as well as intradural; at the craniocervical region, they become intradural after they have either penetrated or circumvented the tectorial membrane to appear in an anterolateral position at the foramen magnum and at $\mathrm{Cl}$ 2 . These lesions, when at the craniocervical region, have been believed to be invariably fatal for patients younger than 5 years of age, regardless of surgical treatment. $6,8,16,23$ Chordomas are well defined, and CT and MR images are of high resolution. ${ }^{43}$ Involvement of the lateral articular masses of the atlas and axis and the occipital condyles were indications for stabilization after resection. Relevant surgical techniques include anterior transpalatopharyngeal and open-door maxillotomy approaches, lateral and posterolateral approaches, and (more recently) endoscopic transoral and transnasal procedures. ${ }^{15,43}$ En bloc resection has been described as a radical procedure with extensive hardware and substantial long-term sequelae.,59 A review by Borba et al. reported the prognosis to be poor for children younger than 5 years of age and worse for those with atypical chordomas. ${ }^{8}$ For adult patients with difficult chordomas, en bloc vertebrectomies are associated with significant morbidity, which markedly alters the quality of life. ${ }^{7,26,59}$ Barrenechea et al. reported that en bloc resections of high cervical chordomas was not feasible. ${ }^{5} \mathrm{Ag}$ gressive resection followed by adjuvant LINAC or protonbeam radiotherapy provides the best results, as exemplified in our series. ${ }^{40,50}$

Fibrous dysplasia in a spinal location with monostotic disease is extremely rare. ${ }^{14,22,27,45}$ Until 2006 , only 25 cases had been reported among patients of all ages. ${ }^{22}$ Between 1996 and 2010, a total of 3 such cases were encountered in the axis body. These lesions arise from bone marrow stomal cells, mostly during the patient's first decade of life, and a few arise later in adulthood. They are lytic with a ground glass appearance, as seen in the cases reported here. Needle biopsy results are usually nondiagnostic, and the treatment goal is resection and stabilization.

Eosinophilic granuloma is the most benign form of disease in the group known as histiocytosis $\mathrm{X}$, which includes Letterer-Siwe and Hand-Schüller-Christian diseases. ${ }^{6}$ Eosinophilic granuloma is considered a benign os- teolytic disease that primarily involves the skull, ribs, and long bones. Reportedly, $80 \%$ of patients are younger than 20 years of age. Of all bone tumors, $6.3 \%-25 \%$ are spinal eosinophilic granulomas. ${ }^{31,57}$ The 2 major radiographic findings are 1) osteolytic defect with occasional sclerotic reaction and 2) grades of vertebral collapse. Atypical lytic lesions might require biopsy; if neurological compromise is present, decompression and stabilization might be required. ${ }^{48,57}$ Greenlee et al. reviewed the series reported by one of our authors (A.H.M.) and presented a decision tree for management of patients with suspected eosinophilic granuloma. ${ }^{31}$ Although eosinophilic granuloma is the most common cause of vertebra plana, diagnosis of additional entities such as Ewing's sarcoma, other tumors, or tuberculosis might require CT-guided biopsy. Lytic forms of eosinophilic granuloma need to be differentiated from osteochondritis, tuberculosis, osteomyelitis, and plasmacytoma. For most children, spinal eosinophilic granuloma can be managed nonsurgically. A CT-guided biopsy can aid in diagnosis. In our general series of eosinophilic granulomas, diagnosis for 8 of 12 patients required a tissue biopsy. The length of spinal immobilization was determined by patient symptoms and radiographic improvement. ${ }^{31}$

Ewing's sarcoma is a rare, aggressive, primitive neuroectodermal tumor usually seen in children. ${ }^{68}$ It may also be a primary spinal epidural lesion. ${ }^{34,49}$ Only $3.5 \%$ of patients have primary Ewing's sarcoma of the spine; when the sacrum is excluded, this percentage decreases to $1 \%$. Among patients with Ewing's sarcoma, 58\% have neurologic deficits. For patients who undergo resection, radiation, and chemotherapy, the 5-year survival rate is $33 \%$.1,67 The development of effective chemotherapy has been the main factor for overall improvement and disease-free survival among these patients; the 5-year survival rate is $70 \% .^{53}$ A review of the St. Jude's Children's Research Hospital identified 344 patients with Ewing's sarcoma, of which 33 tumors were primary tumors in the vertebra. ${ }^{67}$ Only 2 were in the cervical location. The event-free survival rate $( \pm \mathrm{SD})$ was $48 \% \pm 8.9 \%$.

\section{Conclusions}

We described a large series of primary atlantoaxial tumors in children for whom current technological advances were used and follow-up duration was long. For most cases, high-definition neurodiagnostic imaging has facilitated diagnosis of primary bone tumors in children. However, when the diagnosis remains in question, a CTguided biopsy is possible. En bloc resection of tumors at the atlantoaxial region would be ideal, but such resection is unlikely unless the area of pathology is small and focal. Angiography and tumor embolization improve surgical safety and, hence, play a major role in surgical management. Most primary bone tumors in children, except chordomas and Ewing's sarcomas, are benign. Thus, to achieve the same result as an en bloc resection, a staged approach is recommended, except for chordomas, for which a gross resection should be followed with radiation therapy.

Axis corpectomy necessitates bone placement in the C-2 body and dorsal stabilization. Aneurysmal bone cysts can be treated with embolization and stabilization except 
for patients with an extensive lesion with collapse and neurologic deficit. For these patients, decompression is necessary.

Diagnosis of eosinophilic granulomas might require biopsy. Fusion and stabilization are essential if skeletal instability is present. Patients with disseminated disease (histiocytosis $\mathrm{X}$ ) respond well to chemotherapy.

\section{Disclosure}

The authors report no conflict of interest concerning the materials or methods used in this study or the findings specified in this paper.

Author contributions to the study and manuscript preparation include the following. Conception and design: Menezes. Acquisition of data: both authors. Analysis and interpretation of data: both authors. Drafting the article: both authors. Critically revising the article: both authors. Reviewed submitted version of manuscript: both authors. Approved the final version of the manuscript on behalf of both authors: Menezes. Administrative/technical/material support: Menezes. Study supervision: Menezes.

\section{References}

1. Akeda K, Kasai Y, Kawakita E, Seto M, Kono T, Uchida A: Primary Ewing sarcoma of the spine mimicking a psoas abscess secondary to spinal infection. Spine (Phila Pa 1976) 34: E337-E341, 2009

2. Ameli NO, Abbassioun K, Saleh H, Eslamdoost A: Aneurysmal bone cysts of the spine. Report of 17 cases. J Neurosurg 63:685-690, 1985

3. Azouz EM, Kozlowski K, Marton D, Sprague P, Zerhouni A, Asselah F: Osteoid osteoma and osteoblastoma of the spine in children. Report of 22 cases with brief literature review. Pediatr Radiol 16:25-31, 1986

4. Bandiera S, Boriani S, Donthineni R, Amendola L, Cappuccio $\mathrm{M}$, Gasbarrini A: Complications of en bloc resections in the spine. Orthop Clin North Am 40:125-131, vii, 2009

5. Barrenechea IJ, Perin NI, Triana A, Lesser J, Costantino P, Sen C: Surgical management of chordomas of the cervical spine. J Neurosurg Spine 6:398-406, 2007

6. Beer SJ, Menezes AH: Primary tumors of the spine in children. Natural history, management, and long-term follow-up. Spine (Phila Pa 1976) 22:649-659, 1997

7. Biagini R, Casadei R, Boriani S, Erba F, Sturale C, Mascari C, et al: En bloc vertebrectomy and dural resection for chordoma: a case report. Spine (Phila Pa 1976) 28:E368-E372, 2003

8. Borba LAB, Al-Mefty O, Mrak RE, Suen J: Cranial chordomas in children and adolescents. J Neurosurg 84:584-591, 1996

9. Boriani S, De Iure F, Campanacci L, Gasbarrini A, Bandiera $\mathrm{S}$, Biagini R, et al: Aneurysmal bone cyst of the mobile spine: report on 41 cases. Spine (Phila Pa 1976) 26:27-35, 2001

10. Boriani S, Weinstein JN, Biagini R: Primary bone tumors of the spine. Terminology and surgical staging. Spine (Phila Pa 1976) 22:1036-1044, 1997

11. Burn SC, Ansorge O, Zeller R, Drake JM: Management of osteoblastoma and osteoid osteoma of the spine in childhood. Clinical article. J Neurosurg Pediatr 4:434-438, 2009

12. Capanna R, Bettelli G, Biagini R, Ruggieri P, Bertoni F, Campanacci M: Aneurysmal cysts of long bones. Ital J Orthop Traumatol 11:409-417, 1985

13. Chatzidakis E, Lypiridis S, Kazdaglis G, Chatzikonstadinou K, Papatheodorou G: A rare case of solitary osteochondroma of the dens of the C2 vertebra. Acta Neurochir (Wien) 149:637638,2007

14. Chi JH, Bydon A, Hsieh P, Witham T, Wolinsky JP, Gokaslan ZL: Epidemiology and demographics for primary vertebral tumors. Neurosurg Clin N Am 19:1-4, 2008
15. Choi D, Melcher R, Harms J, Crockard A: Outcome of 132 operations in 97 patients with chordomas of the craniocervical junction and upper cervical spine. Neurosurgery 66:59-65, 2010

16. Choi GH, Yang MS, Yoon H, Shin HC, Kim KN, Yi S, et al: Pediatric cervical chordoma: report of two cases and a review of the current literature. Childs Nerv Syst 26:835-840, 2010

17. Cloft HJ, Dion JE: Preoperative and palliative embolization of vertebral tumors. Neuroimaging Clin N Am 10:569-578, 2000

18. Cové JA, Taminiau AH, Obermann WR, Vanderschueren GM: Osteoid osteoma of the spine treated with percutaneous computed tomography-guided thermocoagulation. Spine (Phila Pa 1976) 25:1283-1286, 2000

19. De Cristofaro R, Biagini R, Boriani S, Ricci S, Ruggieri P, Rossi G, et al: Selective arterial embolization in the treatment of aneurysmal bone cyst and angioma of bone. Skeletal Radiol 21:523-527, 1992

20. DeRosa GP, Graziano GP, Scott J: Arterial embolization of aneurysmal bone cyst of the lumbar spine. A report of two cases. J Bone Joint Surg Am 72:777-780, 1990

21. Enneking WF, Spanier SS, Goodman MA: A system for the surgical staging of musculoskeletal sarcoma. Clin Orthop Relat Res (153):106-120, 1980

22. Fenoy AJ, Greenlee JDW, Menezes AH, Donovan KA, Sato Y, Hitchon PW, et al: Primary bone tumors of the spine in children. J Neurosurg 105 (4 Suppl):252-260, 2006

23. Ferraresi V, Nuzzo C, Zoccali C, Marandino F, Vidiri A, Salducca N, et al: Chordoma: clinical characteristics, management and prognosis of a case series of 25 patients. BMC Cancer 10:22, 2010

24. Figarella-Branger D, Perez-Castillo M, Garbe L, Grisoli F, Gambarelli D, Hassoun J: Malignant transformation of an osteoblastoma of the skull: an exceptional occurrence. Case report. J Neurosurg 75:138-142, 1991

25. Fisher CG, Keynan O, Boyd MC, Dvorak MF: The surgical management of primary tumors of the spine: initial results of an ongoing prospective cohort study. Spine (Phila Pa 1976) 30:1899-1908, 2005

26. Fujita T, Kawahara N, Matsumoto T, Tomita K: Chordoma in the cervical spine managed with en bloc excision. Spine (Phila Pa 1976) 24:1848-1851, 1999

27. Garg S, Dormans JP: Tumors and tumor-like conditions of the spine in children. J Am Acad Orthop Surg 13:372-381, 2005

28. Garg S, Mehta S, Dormans JP: Modern surgical treatment of primary aneurysmal bone cyst of the spine in children and adolescents. J Pediatr Orthop 25:387-392, 2005

29. Gelberman RH, Olson CO: Benign osteoblastoma of the atlas. A case report. J Bone Joint Surg Am 56:809-810, 1974

30. Gellad FE, Sadato N, Numaguchi Y, Levine AM: Vascular metastatic lesions of the spine: preoperative embolization. Radiology 176:683-686, 1990

31. Greenlee JDW, Fenoy AJ, Donovan KA, Menezes AH: Eosinophilic granuloma in the pediatric spine. Pediatr Neurosurg 43:285-292, 2007

32. Hadjipavlou AG, Tzermiadianos MN, Kakavelakis KN, Lander P: Percutaneous core excision and radiofrequency thermocoagulation for the ablation of osteoid osteoma of the spine. Eur Spine J 18:345-351, 2009

33. Hladky JP, Lejeune JP, Singer B, Lecomte-Houcke M, Herbaux B, Dhellemmes P: Osteoblastoma of the odontoid process. Pediatr Neurosurg 21:260-262, 1994

34. Hsieh CT, Chiang YH, Tsai WC, Sheu LF, Liu MY: Primary spinal epidural Ewing sarcoma: a case report and review of the literature. Turk J Pediatr 50:282-286, 2008

35. Julien J, Riemens V, Vital C, Lagueny A, Miet G: Cervical cord compression by solitary osteochondroma of the atlas. J Neurol Neurosurg Psychiatry 41:479-481, 1978

36. Kaner T, Sasani M, Oktenoglu T, Aydin S, Ozer AF: Osteoid 
osteoma and osteoblastoma of the cervical spine: the cause of unusual persistent neck pain. Pain Physician 13:549-554, 2010

37. Lis E, Bilsky MH, Pisinski L, Boland P, Healey JH, O'Malley $\mathrm{B}$, et al: Percutaneous CT-guided biopsy of osseous lesion of the spine in patients with known or suspected malignancy. AJNR Am J Neuroradiol 25:1583-1588, 2004

38. Lotfinia I, Vahedi P, Tubbs RS, Ghavame M, Meshkini A: Neurological manifestations, imaging characteristics, and surgical outcome of intraspinal osteochondroma. Clinical article. J Neurosurg Spine 12:474-489, 2010

39. MacGee EE: Osteochondroma of the cervical spine: a cause of transient quadriplegia. Neurosurgery 4:259-260, 1979

40. Menezes AH: Clival and craniovertebral junction chordomas. World Neurosurg [epub ahead of print], 2013

41. Menezes AH: Craniovertebral junction neoplasms in the pediatric population. Childs Nerv Syst 24:1173-1186, 2008

42. Menezes AH, Sato Y: Primary tumors of the spine in children-natural history and management. 1990. Pediatr Neurosurg 23:101-114, 1995

43. Menezes AH, Traynelis VC: Tumors of the craniovertebral junction, in Winn HR (ed): Youmans Neurological Surgery. Philadelphia: Elsevier, 2011, pp 3114-3130

44. Merryweather R, Middlemiss JH, Sanerkin NG: Malignant transformation of osteoblastoma. J Bone Joint Surg Br 62: $381-384,1980$

45. Mezzadri JJ, Acotto CG, Mautalen C, Basso A: Surgical treatment of cervical spine fibrous dysplasia: technical case report and review. Neurosurgery 44:1342-1347, 1999

46. Myles ST, MacRae ME: Benign osteoblastoma of the spine in childhood. J Neurosurg 68:884-888, 1988

47. Novais EN, Rose PS, Yaszemski MJ, Sim FH: Aneurysmal bone cyst of the cervical spine in children. J Bone Joint Surg Am 93:1534-1543, 2011

48. Osenbach RK, Youngblood LA, Menezes AH: Atlanto-axial instability secondary to solitary eosinophilic granuloma of $\mathrm{C} 2$ in a 12-year-old girl. J Spinal Disord 3:408-412, 1990

49. Ozturk E, Mutlu H, Sonmez G, Vardar Aker F, Cinar Basekim C, Kizilkaya E: Spinal epidural extraskeletal Ewing sarcoma. J Neuroradiol 34:63-67, 2007

50. Pallini R, Maira G, Pierconti F, Falchetti ML, Alvino E, Cimino-Reale G, et al: Chordoma of the skull base: predictors of tumor recurrence. J Neurosurg 98:812-822, 2003

51. Palmer FJ, Blum PW: Osteochondroma with spinal cord compression. Report of three cases. J Neurosurg 52:842-845, 1980

52. Papagelopoulos PJ, Currier BL, Shaughnessy WJ, Sim FH, Ebsersold MJ, Bond JR, et al: Aneurysmal bone cyst of the spine. Management and outcome. Spine (Phila Pa 1976) 23: 621-628, 1998

53. Paulino AC, Nguyen TX, Mai WY: An analysis of primary site control and late effects according to local control modality in non-metastatic Ewing sarcoma. Pediatr Blood Cancer 48: 423-429, 2007

54. Pearl MS, Wolinsky JP, Gailloud P: Preoperative embolization of primary spinal aneurysmal bone cysts by direct percutaneous intralesional injection of n-butyl-2-cyanoacrylate. J Vasc Interv Radiol 23:841-845, 2012

55. Perlmutter DH, Campbell S, Rubery PT, Vates EG, Silberstein HJ: Aneurysmal bone cyst: surgical management in the pediatric cervical spine. Spine (Phila Pa 1976) 34:E50-E53, 2009

56. Piper JG, Menezes AH: Management strategies for tumors of the axis vertebra. J Neurosurg 84:543-551, 1996

57. Raab P, Hohmann F, Kühl J, Krauspe R: Vertebral remodeling in eosinophilic granuloma of the spine. A long-term follow-up. Spine (Phila Pa 1976) 23:1351-1354, 1998
58. Rai AT, Collins JJ: Percutaneous treatment of pediatric aneurysmal bone cyst at $\mathrm{Cl}$ : a minimally invasive alternative: a case report. AJNR Am J Neuroradiol 26:30-33, 2005

59. Rhines LD, Fourney DR, Siadati A, Suk I, Gokaslan ZL: En bloc resection of multilevel cervical chordoma with C-2 involvement. Case report and description of operative technique. J Neurosurg Spine 2:199-205, 2005

60. Roach JW, Klatt JWB, Faulkner ND: Involvement of the spine in patients with multiple hereditary exostoses. J Bone Joint Surg Am 91:1942-1948, 2009

61. Scheer JK, Tang J, Eguizabal J, Farin A, Buckley JM, Deviren $\mathrm{V}$, et al: Optimal reconstruction technique after C-2 corpectomy and spondylectomy: a biomechanical analysis. Laboratory investigation. J Neurosurg Spine 12:517-524, 2010

62. Schomacher M, Suess O, Kombos T: Osteochondromas of the cervical spine in atypical location. Acta Neurochir (Wien) 151:629-633, 2009

63. Smith TP, Gray L, Weinstein JN, Richardson WJ, Payne CS: Preoperative transarterial embolization of spinal column neoplasms. J Vasc Interv Radiol 6:863-869, 1995

64. Srikantha U, Bhagavatula ID, Satyanarayana S, Somanna S, Chandramouli BA: Spinal osteochondroma: spectrum of a rare disease. Report of 3 cases. J Neurosurg Spine 8:561-566, 2008

65. Tubbs RS, Maddox GE, Grabb PA, Oakes WJ, Cohen-Gadol AA: Cervical osteochondroma with postoperative recurrence: case report and review of the literature. Childs Nerv Syst 26: 101-104, 2010

66. Unni KK: Dahlin's Bone Tumors: General Aspects and Data on 11,087 Cases, ed 5. Philadelphia: Lippincott-Raven, 1996

67. Venkateswaran L, Rodriguez-Galindo C, Merchant TE, Poquette CA, Rao BN, Pappo AS: Primary Ewing tumor of the vertebrae: clinical characteristics, prognostic factors, and outcome. Med Pediatr Oncol 37:30-35, 2001

68. Weber KL: Current concepts in the treatment of Ewing's sarcoma. Expert Rev Anticancer Ther 2:687-694, 2002

69. Yamazaki T, McLoughlin GS, Patel S, Rhines LD, Fourney DR: Feasibility and safety of en bloc resection for primary spine tumors: a systematic review by the Spine Oncology Study Group. Spine (Phila Pa 1976) 34 (22 Suppl):S31-S38, 2009

70. Yang X, Wu Z, Xiao J, Teng H, Feng D, Huang W, et al: Sequentially staged resection and 2-column reconstruction for C2 tumors through a combined anterior retropharyngeal-posterior approach: surgical technique and results in 11 patients. Neurosurgery 69 (2 Suppl Operative):ons184-ons194, 2011

71. Zenonos G, Jamil O, Governale LS, Jernigan S, Hedequist D, Proctor MR: Surgical treatment for primary spinal aneurysmal bone cysts: experience from Children's Hospital Boston. Clinical article. J Neurosurg Pediatr 9:305-315, 2012

Manuscript submitted May 14, 2013.

Accepted November 25, 2013.

Portions of this work were presented in oral form at the 36th Annual Meeting of The American Society of Pediatric Neurosurgeons, February 10-15, 2013, Kauai, Hawaii.

Please include this information when citing this paper: published online January 17, 2014; DOI: 10.3171/2013.11.PEDS13245.

Address correspondence to: Arnold H. Menezes, M.D., Department of Neurosurgery, University of Iowa Hospitals and Clinics, 200 Hawkins Dr., 1824 JPP, Iowa City, IA 52242. email: arnold-menezes@uiowa.edu. 